\title{
AIMÉ BONPLAND E A AVALIAÇÃO DE RECURSOS EM SANTA CRUZ, 1849-50
}

\section{Stephen Bell*}

RESUMO: Com suas longas viagens pela América do Sul meridional, Aimé Bonpland (1773-1858) abriu um canal evidente para a difusão de idéias sobre novas formas de uso da terra. Este trabalho se concentra em 1849 e 1850 , anos férteis para as explorações de Bonpland, assinalados por sua primeira avaliação de recursos de partes da Serra do Rio Grande do Sul. A exploração científica apoiava-se em seus projetos para o desenvolvimento rural integrado nas terras pioneiras de Santa Cruz, que estimularam a criação de merinos para extração da lã lado a lado com o cultivo sustentável do mate. O trabalho situa as atividades de Bonpland em 1849-50, num contexto relacionado a sua carreira anterior. Para ele, o desenvolvimento regional da Serra incluía acentuada ênfase à proteção de recursos naturais, o que colidia com os objetivos do governo imperial, ansioso por abrir as terras de floresta do sul do Brasil à colonização em grande escala. No meio cultural do Rio Grande do Sul da metade do século, a audiência interessada nos planos de Bonpland para diversificação econômica foi diminuta. Uma vida migratória dispersou suas energias e reduziu-lhes o impacto potencial - um impacto talvez ainda mais amortecido por sua abordagem descontraída em relação ao tempo.

- Professor da Universidade McGill - Montreal-Canadá. (Traduzido do inglês por Carmen Vera Cirne Lima).

1 Agradeço o apoio financeiro do Social Sciences and Humanities Research Council of Canada/Conseil de recherche en sciences humaines du Canada. Uma versâo resumida deste trabalho foi publicada sob o título "Aimé Bonpland: un novateur optimiste dans le Sud-Brésil", trad. Philippe Jansen, em Découvertes et Explorateurs: Actes du Colloque International. Bordeaux 12-14 Juin 1992 (Paris, 1994), p. 133-42. Este colóquio foi organizado por Histoire au Présent e pela Maison des Pays Ibériques, Université Michel de Montaigne - Bordeaux III.

Estudos Ibero-Americanos. PUCRS, v.XXI, n.2, p. 63-79, dezembro, 1995 


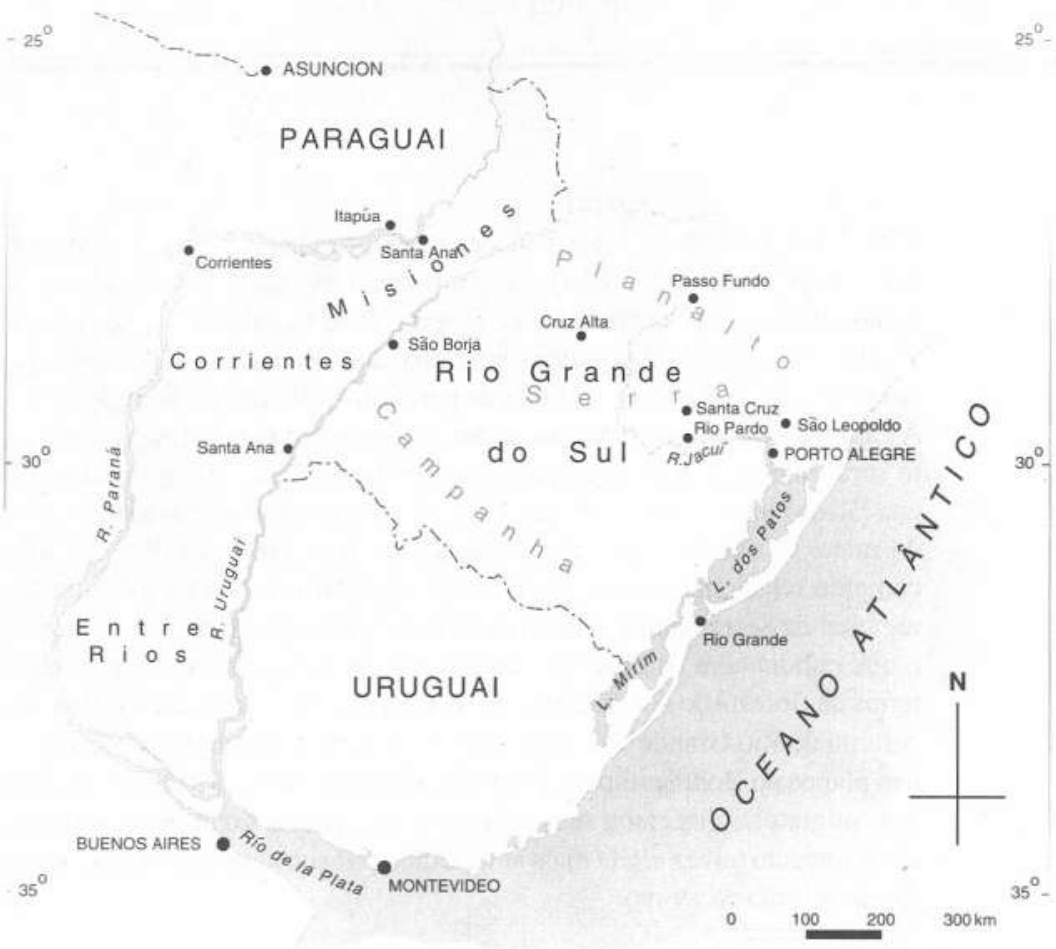

Mapa 1 - O campo de ação de Bonpland na América do Sul 


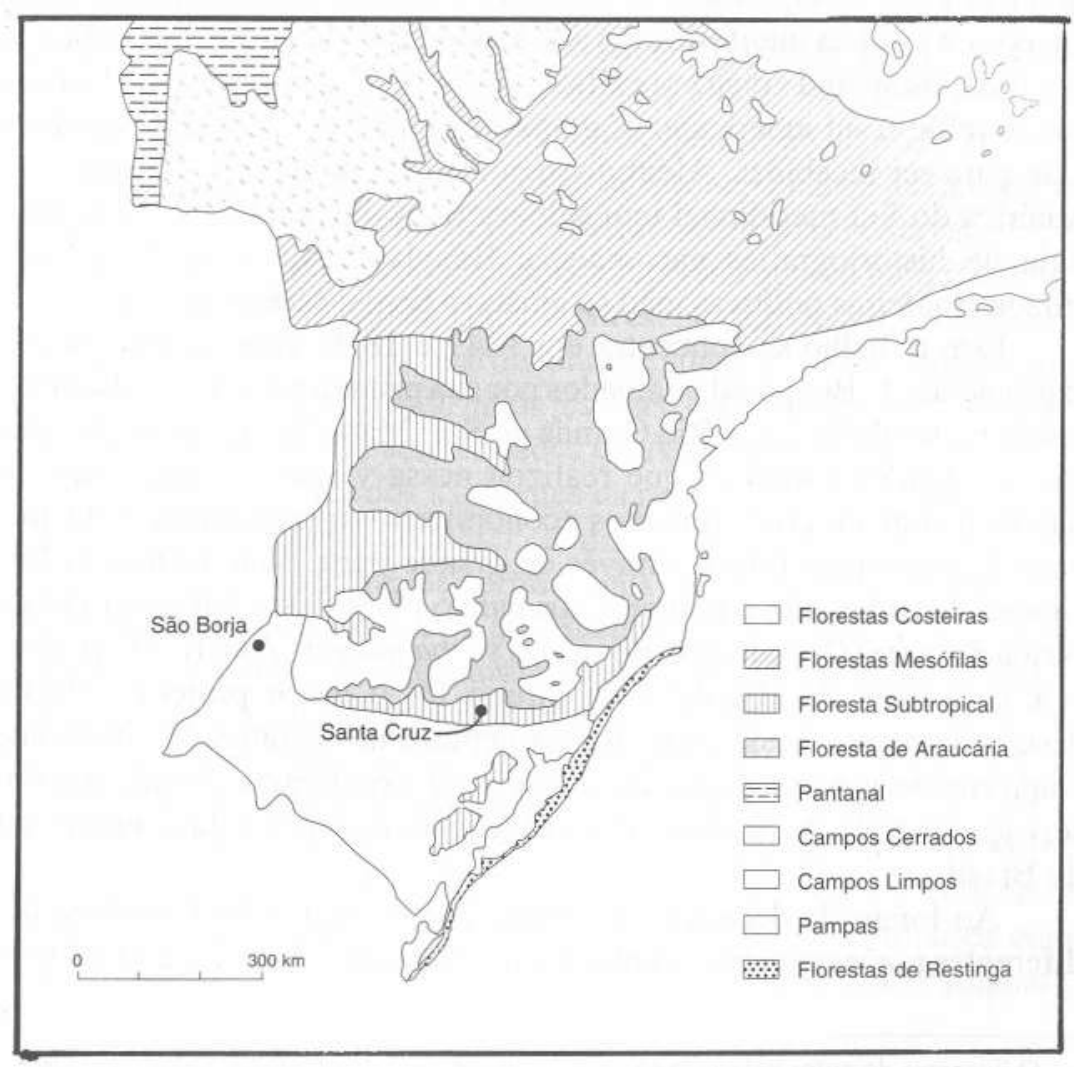

Mapa 2 - Vegetação natural no sul do Brasil 
Aimé Bonpland (1773-1858) ficou famoso ainda jovem devido a viagens científicas feitas em colaboração com Alexander von Humboldt pelo norte da América do Sul (1799-1804) Sua longa carreira na parte meridional da América Latina permanece obscura, especialmente a última fase. ${ }^{2}$ Existem explicações claras para isso. Em primeiro lugar, na América Espanhola, durante a transição longa e tumultuada de colônia a nações, a política interferia com as linhas de comunicação. Por períodos extensos, Bonpland viveu em exílio - voluntário ou imposto - da Europa no seu refúgio sul-americano. Cartas da Europa por vezes levavam anos a fio para ser recebidas. Além disso, a história do desenvolvimento da América do Sul meridional tem sido escrita principalmente como uma série de historiografias nacionais, e Bonpland, que com freqüência cruzou fronteiras políticas, não se ajustava bem a esse esquema.

Este trabalho se concentra em 1849 e 1850 , anos férteis para as explorações de Bonpland, marcados por sua primeira avaliação de recursos de partes da Serra do Rio Grande do Sul (Mapa 1). As descrições das várias espécies botânicas que realizou nessa viagem foram resultado secundário de empreendimentos econômicos - a transferência de animais do oeste para o leste através de grande parte do território do Rio Grande do Sul, assim como projetos para o plantio ou colheita em larga escala de mate (Ilex paraguariensis), a yerba mate da América Espanhola e erva-mate do Brasil. ${ }^{3}$ Esse último foi o único projeto sério de desenvolvimento nesse país, basicamente uma tentativa de transferir conhecimentos acumulados em décadas de experiência científica e observação prática na América Espanhola para as regiões da fronteira sul do Brasil.

Ao longo de décadas, vários projetos tinham sido lançados; por diferentes razões externas, nenhum deles havia resistido. Para situar num

2 O interesse do autor pela vida sul-americana de Bonpland foi estimulado pelo breve relato feito por Abeillard Barreto em sua monumental Bibliografia sul-riograndense, 2 vols. (Rio de Janeiro, 1973, 1976), vol. 1, p. 174-82. George Sarton, em importante ensaio destinado a retirar Bonpland da obscuridade (um item que Barreto não percebeu), não viu razão para seguir a carreira posterior, "Aimé Bonpland (17731858)," Isis 34 (1943), p. 387, 391-92.

3 Para detalhes relativos à preparação e comercialização deste produto, ver especialmente Thomas Whigham, The Politics of the River Trade: Tradition and Development in the Upper Plata 1780-1870 (Albuquerque, N. Mex., 1991), p. 107-32; sobre Bonpland e mate, ver também Temístocles Linhares, História econômica do mate (Rio de Janeiro, 1969), p. 50-55, 100-101. 
contexto as atividades de Bonpland em meados do século é necessário um breve retrospecto desses projetos.

\section{O Boupland e o Desenvolvimento de Recursos (1817-47)}

Bonpland chegou ao Rio da Prata quase no final de 1816, trazendo consigo vasta bagagem que incluía sementes e duas mil plantas vivas. ${ }^{4}$ As expectativas da elite de Buenos Aires quanto ao que ele poderia realizar eram enormes, entre elas a idéia de que seria capaz de introduzir novos métodos de agricultura prática baseados em suas observações na Inglaterra, França e América. O cientista logo se engajou num reconhecimento botânico da região de Buenos Aires. No fim do ano de 1818, ao investigar a ilha próxima de Martín García, suas descobertas incluíram o que restava do mate cultivado pelos jesuítas; estes haviam plantado pés de mate aos milhares em suas missões do Alto Prata. ${ }^{5}$ Esse chá verde, elemento básico na dieta dos habitantes da região, parece ter instigado a imaginação de Bonpland. O caráter científico e o potencial comercial do mate tornaram-se preocupações primordiais pelo resto de sua vida.

As tentativas de radicar-se em Buenos Aires pouco progrediram. A instabilidade política e o caráter da sociedade na Buenos Aires revolucionária logo o estavam empurrando para a periferia da periferia, enquanto seguia a bacia do rio Paraná até o Alto Prata. A segunda fase dos seus projetos sul-americanos constituiu-se num esforço para ressuscitar uma plantação de mate estabelecida pelos jesuítas em Santa Ana. ${ }^{6}$ Esforços para reconstruir a economia de uma antiga zona missioneira num território em disputa também o levaram a procurar aliança com quem um autor chamou de "praticamente todos os inimigos do Paraguai",

4 Sarton enfatizou que Bonpland levara "todo seu herbário americano" para a Argentina, op. cit., p. 389. Uma notícia de jornal, da época em que Bonpland chegou a Buenos Aires, enfatizava em vez disso o grande número de espécies européias que ele estava trazendo à Argentina. Crónica Argentina (Buenos Aires), $1^{\circ}$ de fevereiro de 1817, citada em Wllhelm Schulz, Aimé Bonpland Alexander von Humboldts Begleiter auf der Amerikareise 1799-1804: Sein Leben und Wirken, besonders nach 1817 in Argentinien (Mainz, 1960), p. 596.

5 Barreto, op. cit., v. 1, p. 180; Felix Maria Gomez, Amado Bonpland (Corrientes, 1958), p. 17.

6 Schulz, op. cit., p. 604-7. 
o que resultou finalmente numa detenção superior a nove anos nesse país (dezembro de 1821 a janeiro de 1831).

$\mathrm{O}$ que permaneceu gravado na imaginação popular, da época e desde então, foi a imagem de um cientista de fama internacional sendo preso e arrastado através do Paraná até o Paraguai. Detido lá indefinidamente, Bonpland não teve escolha a não ser lançar raízes. Estabeleceu-se perto de Santa Maria, onde tirou pleno proveito de seus múltiplos talentos no desenvolvimento de uma pequena destilaria, uma oficina de carpintaria e ferraria, e um pequeno hospital. De vez que isso não lhe ocupava todo o tempo, também se dedicou "par goût et par besoin à l'agricultu$r e$ ", uma atividade que lhe trazia "jouissances infinies" ${ }^{8}$. Num estabelecimento rural integrado, criou gado mas também cultivou algodão, cana-de-açúcar e mate; alegou que tentava desenvolver na agricultura paraguaia "les méthodes perfectionnées et plus rationnelles de l'Europe", embora o que quisesse dizer com isso ainda precise ser esclarecido.'

Ao ser libertado da longa detenção no Paraguai, usou uma das poucas saídas disponíveis, a rota comercial estabelecida de Itapúa ao Brasil, chegando a São Borja, centro administrativo do antigo distrito missioneiro jesuítico do Rio Grande do Sul, em fevereiro de 1831 . Por volta de 1830 , a geografia econômica de São Borja refletia pouco de quaisquer glórias passadas no tempo dos jesuítas. Era uma cidade pobre, na qual a maioria da população se ocupava da agricultura de subsistência; mesmo assim, a localização estratégica do povoado fazia dele "o elo vital numa rede de comércio que se estendia de Assunção e Corrientes até Montevidéu"..$^{10}$ Nos arredores de São Borja, Bonpland repetiu seu conhecido padrão ocupacional do Paraguai, combinando medicina, farmácia e agricultura, inclusive plantio experimental.

Por necessidade e por inclinação, ele foi recuando de volta a Corrientes e Buenos Aires. O contato com a Europa por intermédio de Buenos Aires finalmente lhe trouxe dinheiro (de sua pensão francesa

7 Richard Alan White, Paraguay's Autonomous Revolution. 1810-1840. (Albuquerque, 1978), p. 133. Aimé Bonpland a Domingo Rcguin, São Borja, 22 de fevereiro de 1831, carta publicada no Bulletin de la Societé de Géographie (doravante BSG) n. 99 (julho 1831), p. 41.

9 Alfred Demersay, "Notice sur la vie et les travaux de M. Aimé Bonpland", BSG, $4^{\text {a }}$ ser., 5 (abril 1853), p. 250; a alegação aparece em Bonpland a Adolphe Brunel, carta citada sem fonte em Gomez, op. cit., p. 20-21.

10 Whigham, op. cit., p. 53. 
concedida em 1805) e este o levou a novos projetos, desta vez em Corrientes, de modo que mantinha residências nos dois lados do rio Uruguai. Em setembro de 1837 ele requereu terras, anunciando a intenção de plantar mate como parte de sua justificativa. ${ }^{11}$ Cinco meses depois o governo de Corrientes lhe concedeu uma área de cinco léguas quadradas (13.500 hectares) em Santa Ana. ${ }^{12}$ Nessa terra, começou a carreira de criador, com mulas e cavalos mas especialmente cinco mil ovinos da raça merino, um rebanho muito grande para essa região e época. A política logo voltou a interferir. Corrientes declarou guerra a Juan Manuel de Rosas (1793-1877) em fevereiro de 1839. Seguiu-se a isso, pouco tempo depois, a batalha de Pago Largo, em que Corrientes sofreu esmagadora derrota. ${ }^{13}$ Os anos seguintes são um vazio em termos de qualquer progresso econômico, com Bonpland envolvido no labirinto da luta unitária contra Rosas e seu modelo federal para a Argentina dominado por Buenos Aires.

\section{Os Projetos de Desenvolvimento de Bonpland no Brasil (1847-50)}

A viagem de Bonpland de 1849, através de partes da Serra do Rio Grande do Sul, representa um rompimento com seu passado. Esta foi a primeira viagem em décadas a afastá-lo das bacias do rio da Prata, e sua primeira ao interior do Brasil. Embora as características botânicas da região a leste das missões já the viessem despertando a curiosidade há muito tempo, suas cartas revelam claramente que ele foi empurrado em 1849-50 de Corrientes para o Brasil pela política do Prata. Após 1835, por dez anos o Rio Grande do Sul fora palco de uma guerra civil. No final da década de 1840, ao contrário dos vizinhos, estava em paz. Como aconteceu tão freqüentemente com Bonpland, o catalisador da viagem foi uma amizade rapidamente estabelecida, neste caso com o criador Antônio Rodrigues Chaves, que em 1847 o encontrou em São Borja, provavelmente pela primeira vez. Chaves, cuja família formou parte da elite política do Rio Grande do Sul, residia em Porto Alegre, mas também

11 Partes da requisição de terras são citadas em Gomez, op. cit., p. 26-27.

12 Uma segunda Santa Ana para Bonpland, desta vez no sul de Corrientes.

13 John Lynch, Argentine Dictator: Juan Manuel de Rosas. 1829-1852. (Oxford, 1981), especialmente p. 202. 
possuía a fazenda Santa Cruz na orla do Planalto Meridional do Brasil. A idéia de que Bonpland viria a vender ovelhas merino a Chaves foi incutida durante a visita deste último a São Borja.

Uma série de cartas de Bonpland a Chaves a respeito deste empreendimento se estende de agosto de 1847 até pouco antes de sua partida, em fevereiro de 1849 , um período de preparação para a viagem de quase dois anos. ${ }^{14}$ Embora Chaves tivesse obviamente suscitado as expectativas de Bonpland para uma venda de gado enquanto em São Borja, ele não se comprometeu até setembro de 1848 . O propósito principal do grande número de cartas era aumentar a confiança de Chaves na idéia de criar merinos por sua boa lã, um empreendimento que, Bonpland repetidamente insistiu, seria lucrativo. ${ }^{15} \mathrm{Na}$ mesma correspondência, demonstrava grande interesse num projeto casado de cultivar mate em enorme escala em Santa Cruz, assim que o negócio dos merinos pudesse ser concluído. ${ }^{16}$

As primeiras cartas a Chaves preocupam-se com a política e com o resgate de animais da Corrientes dilacerada pela guerra. O Rio Grande do Sul serviu para Bonpland como um refúgio da instabilidade crônica de Corrientes nesse período; isso pode ser inferido de sua menção à prudência de ficar "nos grandes bosques". ${ }^{17}$ Um comentário sobre a possibilidade de vir a se estabelecer em Santa Cruz deve ser interpretado da mesma maneira. ${ }^{18}$

A partir de março de 1848, a correspondência de Bonpland com Chaves tornou-se regular (uma carta por mês de março a julho), sinal de que estava aumentando a pressão para vender animais. Uma visita a Corrientes em abril, com o fim de verificar novas perdas causadas por diferentes pilhagens políticas, certamente fortaleceu sua determinação de fazer alguma coisa no Brasil. ${ }^{19}$ À medida que the crescia a confiança no futuro de seu rebanho, começou a fazer mais pedidos a Chaves; em junho de 1848 pediu nada menos que dez quadras (17,4 hectares) de terra virgem. Admitindo nada conhecer do micro-clima ou das características

Biblioteca Nacional (doravante BN), Rio de Janeiro, manuscritos I-2, 3, 36.

Bonpland a Antônio Rodrigues Chaves, São Borja, 5 de agosto de 1847 e 5 de março de 1848 . Na carta, Bonpland observou que lãs finas estavam mais caras do que nunca nos mercados da Europa e da América do Norte.

BN, Bonpland a Chaves, 2 de maio de 1848.

BN, Bonpland a Chaves, 5 de agosto de 1847 e 5 de março de 1848 .

BN, Bonpland a Chaves, 2 de maio de 1848.

BN, Bonpland a Chaves, 25 de abril de 1848. 
da terra de Santa Cruz, sugeriu tentar uma série de culturas, incluindo mandioca, batata inglesa e doce, milho, abóbora, grãos e legumes. Esta lista teria causado pouca surpresa ao destinatário, pois era constituída principalmente de elementos conhecidos da cultura indígena nas missões. Um interesse por plantas forrageiras era muito mais inovador. Bonpland escreveu a Chaves que estavam cultivando com sucesso grama de Angola (Panicum purpurascens) em São Borja e sugeriu experiências em Santa Cruz com todas as plantas forrageiras identificadas, tanto nativas quanto exóticas. ${ }^{20}$

Bonpland precisava do dinheiro que essa venda a Chaves lhe traria. Enquanto o inverno começava a dar lugar à primavera, a falta de notícias do amigo arrefeceu seu ânimo extraordinariamente exuberante. ${ }^{21} \mathrm{Na}$ verdade, este já havia mandado confirmação na carta de setembro de 1848 . $^{22}$ A escolha desse momento pode ser significativa, pois o Rio Grande do Sul havia recentemente promulgado uma lei (131, de 12 de julho de 1848) destinada a fomentar o melhoramento de raças de animais na província, subsidiando um centro de coudelaria. A lei era parte do esforço modernizador do General Andréa (presidente da província de 10 de abril de 1848 a 6 de março de 1850$).{ }^{23}$ Não sabemos se teve qualquer influência no pensamento de Chaves, mas certamente encorajou Bonpland, que leu sobre ela nos jornais de Porto Alegre e insistiu com Chaves para que fizesse o possível de modo a assegurar a reputação do rebanho de Santa Cruz, já com planos de que servisse como banco genético para os estancieiros em geral. ${ }^{24}$

Conduzir uma caravana de 562 ovelhas, cavalos e mulas ao longo de quase 500 quilômetros até Santa Cruz foi em si um ato de exploração geográfica. Ao delinear uma rota, Bonpland procurava ajuda no mapa de Zambeccari de 1830 , mas esse de pouco lhe serviu. ${ }^{25}$ Decidiu fazer uma

20 BN, Bonpland a Chaves, 24 de junho de 1848; sobre as características da agricultura indígena, ver especialmente a descrição feita por Auguste de Saint-Hilaire em 1821 da antiga missāo de São Luís, Viagem ao Rio Grande do Sul. 1820-21, trad. Leonam de Azeredo Penna (Belo Horizonte e São Paulo, 1974), p. 148, publicada originalmente como Voyage à Rio Grande do Sul. Brésil. (Orléans, 1887).

BN, Bonpland a Chaves, 5 de outubro de 1848.

BN, Bonpland a Chaves, 9 de outubro de 1848 .

Francisco José de Sousa Soares de Andréa, mais tarde Barăo de Caçapava (17811858).

BN, Bonpland a Chaves, 9 de outubro de 1848.

BN, Bonpland a Chaves, 2 de maio e 24 de junho de 1848 . Conte Livio Zambeccari (1802-62) foi um revolucionário italiano com experiência sul-americana; para detaIhes de seu mapa do Rio Grande do Sul, ver Barreto, op. cit., v. 2, p. 1446-48. 
descrição topográfica do seu caminho para Santa Cruz, determinação que levou a cabo. ${ }^{26}$

Bonpland já tinha setenta e cinco anos quando começou a viagem através da Serra, em fevereiro de 1849 , mas sua energia não havia diminuído; mantinha uma variada série de interesses, como demonstram seus diários de viagem. Os principais motivos econômicos dessa jornada eram entregar animais e avaliar os pés de mate a fim de determinar a possibilidade de uma plantação. Pretendia continuar até Porto Alegre, principalmente para mandar a Paris o certificat de vie necessário ao prolongamento de sua pensão francesa. Também tinha curiosidade em ver a capital da província. Motivos adicionais incluíam a compra de remédios, assim como ver o que poderia ser feito para melhorar a organização dos serviços médicos em São Borja. A viagem de São Borja a Santa Cruz durou vinte e cinco dias; ela levou Bonpland e seus peóes por um território de ocupação muito esparsa, mesmo para padróes regionais. ${ }^{27}$ Durante a viagem para e pelos arredores de Santa Cruz, o cientista identificou espécies de plantas mais rapidamente do que a qualquer altura de sua permanência na América do Sul.

\section{Bonpland em Santa Cruz}

Se a impressão dominante que os europeus têm do Brasil é de um alto grau de uniformidade de sistemas físicos sobre vastas áreas, Santa Cruz era muito diferente. Situada na orla da Serra, oferecia variedade, um forte contraste com os campos ondulados e um tanto monótonos da Campanha. O relevo na área de Santa Cruz varia de 80 a 600 metros e a maior parte do distrito é montanhosa. ${ }^{28} \mathrm{Na}$ metade do século, essa terra ainda estava coberta por uma densa faixa de floresta subtropical (Mapa 2), que dificultava a comunicação entre os campos temperados da

26 Ver ibid., v. 1, p. 181-82 e v. 2, p. 990-95.

27 Aimé Bonpland, Journal voyage de Sn. Borja a La Cierra y a Porto Alegre, transcrição dos manuscritos originais, notas e revisão de Alicia Lourteig(Porto Alegre e Paris, 1978), p. 3-18. Este trabalho se baseia nos manuscritos 208 e 209 da Bibliothèque Centrale du Muséum d'Histoire Naturelle, Paris.

28 Existe uma análise satisfatória do meio-ambiente físico do sul do Brasil em Leo Waibel, "Princípios da colonização européia no sul do Brasil," trad. Orlando Valverde, em Capítulos de geografia tropical e do Brasil, $2^{\sharp}$ ed. (Rio de Janeiro, 1979), p. 227-28. 
Campanha (centro econômico da província) e os do platô ou Planalto. Acima dos 500 metros a floresta subtropical começava a dar lugar ao pinheiro característico (Araucaria angustifolia) do Planalto Meridional do Brasil.

Quando Bonpland chegou a Santa Cruz, a área já era uma das margens mais dinâmicas do Rio Grande do Sul colonizado. Fazia parte do progressista interior de Rio Pardo, importante cidade fortificada do período colonial. Em 1849 Rio Pardo ainda representava uma fronteira nítida: era o lugar em que o viajante vindo do Atlântico era forçado a substituir a viagem de barco a vapor pelo cavalo, muito mais lento. Esforços para abrir estradas de Rio Pardo para a Serra desde cerca de 1820 tinham sido seguidos rapidamente pela especulação de terras luso-brasileiras.

A política agrária era muito dinâmica naqueles anos próximos à metade do século, alimentada em grande parte pela iminente abolição do tráfico internacional de escravos. Em nível nacional, o governo imperial desejava substituir latifúndios por pequenas propriedades. ${ }^{29}$ Pela lei geral 514 , de 28 de outubro de 1848 , cada província recebeu trinta e seis léguas quadradas de terra para colonização. O governo do Rio Grande do Sul respondeu a esse estímulo, planejando um cinturão estratégico de colônias na orla do Planalto, onde os campos davam lugar à floresta. Essas colônias ajudaram a justificar a despesa com a construção de estradas ligando a depressão central do vale do Jacuí ao Planalto. ${ }^{30}$

As bases para uma colônia em Santa Cruz haviam sido lançadas em 1847, em legislação preparatória à construção de estradas. ${ }^{31}$ Estabelecida em 1849, Santa Cruz foi a primeira de uma série de novas colônias alemãs que cobririam a Serra por volta de 1870. A fundação de uma nova colônia num local isolado, uns 150 quilômetros a oeste do próspero povoado alemão mais antigo de São Leopoldo, foi deliberada.

A impressão inicial de Bonpland sobre a fazenda Santa Cruz, de Chaves, foi desfavorável e deteve temporariamente seus projetos. Nada

29 Ver Warren Dean, "Latifundia and Land Policy in Nineteenth-Century Brazil," Hispanic American Historical Review 51. (1971), p. 606-25.

30 Jean Roche, A colonização alemã e o Rio Grande do Sul, trad. Emery Ruas com prefácio de René Poirier, 2 v. (Porto Alegre, 1969), v. 1, p. 100-102, 109-12, publicado originalmente como La colonisation allemande et le Rio Grande do Sul (Paris, 1959).

31 Jean Roche, L'administration de la province du Rio Grande do Sul de 1829 à 1847 (Porto Alegre, 1961), p. 229-30 e nota 138, p. 268. 
havia de notável no aspecto da fazenda em si, exceto por uma alameda de palmeiras. "Si tout cela", observou Bonpland, "était entouré d'un sol unit et couvert de verdure l'habitacion m'aurait plu mais tous ses environs sont remplis de monticules pelées, et denuées de vegetation... ${ }^{132}$ Mais tarde ele foi ao posto, lugar onde eram reunidos os animais da fazenda, a uns treze quilômetros da sede; ali começou a ter impressões bem diferentes. Os pastos eram superiores, o solo melhor para o cultivo e, acima de tudo, havia ricas florestas de pinheiros, algumas das quais continham pés de mate. Bonpland recuperou seu otimismo.

Pressupondo que Chaves pudesse ir adiante, foi forçado a considerar o que exigiria um projeto combinando criação de merinos e plantação de chá, e emperrou na questão da mão-de-obra. Calculou que tal projeto demandaria de quinze a vinte e cinco peões, mas reconheceu que não havia pessoal suficiente para isso na região; de qualquer modo, os salários seriam altos demais. Os trabalhadores precisariam ser trazidos de fora, preferencialmente negros ou índios. Baseado em suas experiências anteriores, Bonpland era grande entusiasta do trabalho indigena:

C'est surtout des indiens qu'il faudrait se procurer. Ces indigenes offrent la classe la plus utiles aux travaux agricoles. C'est aussi la classe la moins ambitieuse \&c. Seulement il faut savoir la traiter et la conduire. ${ }^{33}$

Os planos de usar escravos, ainda que em escala reduzida, mostravam sua ignorância quanto às leis envolvendo políticas agrárias; a lei 514, de 1848, proibia expressamente o uso de trabalho escravo em terras coloniais. $^{34}$

A partir de viagens feitas pelos arredores de Santa Cruz, Bonpland começou a pensar em arrancar a vegetação rasteira da floresta para aproveitar a plantação de mate, em parte para testar sua teoria de que maior exposição à luz solar resultaria num produto de melhor qualidade. Outras excursões o levaram a planejar a abertura de trilhas para o interior das florestas, a fim de avaliar dimensões e características do mate já existente. Descobriu que a extensão das reservas era suficientemente grande para levá-lo a questionar "le desir que j'ai toujours eu de planter un yerbal en plein champ". ${ }^{35}$ Essa opinião se baseava em parte num risco

32 Bonpland, op. cit., p. 18.

33 Ibid., p. 20-21.

34 Ver Roche, Colonização alemã, v. 1, p. 101.

35 Bonpland, op. cit., p. 25. 
climático: sabia, pela observação das plantas locais, que as estações chegavam mais tarde a Santa Cruz do que a qualquer das missōes jesuíticas onde o mate havia sido plantado.

Tinham sido feitas consideráveis experiências com mate, na Serra, antes da chegada de Bonpland. Este descobriu que lá ele era preparado com mais do que a "erva legítima". Os produtores também estavam usando plantas afins, muitas delas descritas de um modo geral como "cauna." Já que alguns desses substitutos produziam um mate mais amargo, os produtores tendiam a acrescentar folhas de plantas aromáticas para melhorar o sabor, falsificações que Bonpland considerou "pardonables et très louables". ${ }^{36}$ Logo começou a fazer experiências simples com as diversas espécies identificadas pela população local, o que aumentou sua inclinação a trabalhar com misturas. ${ }^{37}$ Minuciosas observações de campo nas cercanias de Santa Cruz levaram-no a descrever cinco novas espécies de mate. ${ }^{38}$

A pesquisa científica feita por ele em Santa Cruz foi realizada principalmente devido a um atraso, à espera que Chaves resolvesse o negócio dos animais. É claro que Bonpland não poderia ter chegado até Porto Alegre sem que houvesse uma venda. Chaves voltou de de uma viagem a Passo Fundo na metade de abril e logo lhe comprou 103 cavalos e mulas, se comprometendo, além disso, a formar uma parceria para a criação de merinos. Quando Bonpland chegou a Porto Alegre, em maio, estava seriamente doente (com falência do sistema gástrico) e assim seu diário de viagem pára por algum tempo.

Bonpland fez uma requisição de terras ao longo da estrada para Santa Cruz em 3 de agosto de 1849, pressupondo que estas lhe seriam concedidas em unidades territoriais de um quarto de légua (1.089 hectares), por vezes chamadas "sesmarias de mato". Não esperou em Porto Alegre para insistir no pedido, mas seguiu para Montevidéu, onde permaneceu de 29 de agosto a 7 de outubro. De Montevidéu, tornou a

36 Ibid., p. 30-31.

37 Na viagem de volta a Santa Cruz em novembro de 1849 , ele se interessou pelo problema de quais os tipos de madeira mais indicados para secar as folhas, ibid., p. 74-75.

38 Ver John Miers, "On the History of the 'Maté' Plant, and the Different Species of Ilex employed in the Preparation of the "Yerba de Maté', or Paraguay Tea," The Annals and Magazine of Natural History 8 (1861), p. 219-28 e 389-401. Bonpland enviou espécimes e anotaçōes de Corrientes para Miers, em Londres, em 17 de junho de 1857. 
percorrer o caminho até sua casa, em São Borja, uma viagem que lhe trouxe novas oportunidades de visitas a Porto Alegre, Rio Pardo e ao distrito de Santa Cruz. Na capital, relacionou o essencial de seus projetos agrícolas em "un petit travail" enviado ao General Andréa. ${ }^{39}$

Bonpland parece ainda ter tido pouca ou nenhuma noção de como evoluía a política do governo em relação à terra. De Porto Alegre, voltou a visitar Santa Cruz via Rio Pardo, acompanhando um engenheiro provincial encarregado da supervisão de terras e da preparação de várias dúzias de lotes para os primeiros colonos. Observando esse engenheiro comandar seus trabalhadores alemães na abertura de uma nova picada (trilha na floresta), teve visível evidência de que os lotes - de 77 hectares cada - seriam muito menores do que precisava. ${ }^{40}$

Mais ou menos à mesma época em que os primeiros colonos chegavam a Santa Cruz, Bonpland escreveu a Andréa, de São Borja, perguntando como a terra seria dividida e se a "ferme model" seria localizada ao longo das margens da picada ou em algum outro lugar. Ressaltou o caráter integrado de seus planos, enfatizando seu valor tanto público quanto privado. Não somente buscava melhorar a indústria do mate do sul do Brasil mas também "on devra s'occuper en grand des parties agricoles les plus analogues au climat, au lieu et au terrain". A carta termina com um apelo para a conservação dos recursos naturais. Nela, afirma que o "ancienne habitude" dos trabalhadores da floresta matava as plantas de mate, e solicita uma regulamentação que mantivesse essa gente fora das terras que o governo da província pudesse conceder como fazenda-modelo. ${ }^{41}$ Ele possuía evidências empíricas suficientes para apoiar seu pedido, como revelam suas observações de viagem. ${ }^{42}$

Santa Cruz desenvolveu-se de maneira muito diferente de qualquer coisa imaginada por Bonpland. Uma lei provincial 229, de 4 de dezembro de 1851 , reduziu ainda mais o tamanho dos lotes coloniais, dividindo-os

39 Bonpland, op. cit.,p. 65-66; Bonpland a Andréa, Porto Alegre, 28 de outubro de 1849 , "Note sur l'avantage de cultiver la plante qui fournit le maté, de former des bois de cette plante et d'améliorer la fabrication de l'herbe dite maté", publicado em E. T. Hamy, Aimé Bonpland, médecin et naturaliste, explorateur de l'Amérique du Sud. Sa vie, son oeuvre, sa correspondence. (Paris, 1906), p. 152-56.

40 Bonpland, op. cit., p. 71.

41 Arquivo Histórico do Rio Grande do Sul, correspondência dos presidentes, maço 20, Bonpland a Andréa, São Borja, 24 de dezembro de 1849.

42 O problema principal era que os trabalhadores da floresta arrancavam as folhas de mate sem respeitar as estaçōes, Bonpland, op. cit., p. 37 e 77. 
em unidades de 48 hectares. No mesmo ano, a província assinou um contrato para o recrutamento de colonos. Santa Cruz logo se tornou uma das poucas zonas de comércio agrícola do Rio Grande do Sul no período. ${ }^{43}$

A abertura de estradas ligando o Planalto ao resto do Rio Grande do Sul parece ter tido um forte impacto na produção do mate. A exportação subiu acentuadamente após 1851 , tendo em 1864 seu ponto culminante para o período imperial com 4.976 toneladas, quase cinco vezes maior do que tinha sido em $1850 .^{44}$ A colheita do chá permaneceu quase que exclusivamente em mãos brasileiras e era vista como marginal pela sociedade das colônias alemãs. ${ }^{45}$

Ainda que Andréa tivesse se apressado em fornecer apoio concreto aos projetos de Bonpland, é de duvidar que tivessem tido muito sucesso, dado o que se conhece do caráter de outros empreendimentos econômicos no Rio Grande do Sul na década de 1850 , tais como os esforços do próprio governo da província com a criação de ovelhas importadas da Saxônia. Uma dificuldade importante teria sido certamente a falta de continuidade de administração. ${ }^{46}$ Mas com a remoção de Rosas para a Inglaterra em 1852, Bonpland tornou a voltar sua atenção para Corrientes, onde suas raízes políticas eram muito mais firmes. No início da década de 1850, escrevia relatórios "excessivamente otimistas", num "tom exuberante" para Juan Pujol (o progressista governador de Corrientes, de 1852 a 59) contendo "planos elaborados para o cultivo de yerba e a importação de maquinário". ${ }^{47}$ As idéias de Bonpland encontraram ouvintes mais interessados em Corrientes do que no Rio Grande do Sul; tanto Pujol quanto Andréa eram modernizadores, mas o primeiro possuía bases mais firmes para efetuar mudanças.

43 Roche, Colonização alemã, v. 1, p. 102, 105-6, 274-76.

44 Dados sobre a exportação de mate estão publicados em Whigham, op. cit., p. 128 e Elmar Manique da Silva, "Ligações externas da economia gaúcha (1736-1890)", em RS: Economia e política, ed. José Hildebrando Dacanal e Sergius Gonzaga (Porto Alegre, 1979), p. 86.

Reinhold Friedrich Hensel, "Beiträge zur näheren Kenntniss der brasilianischen Provinz São Pedro do Rio Grande do Sul", Zeitschrift der Gesellschaft für Erdkunde zu Berlin 2 (1867), p. 349-50.

46 Ver Stephen Bell, "Ranching in the Campanha of Rio Grande do Sul, Brazil, 1850-1920: an Historical Geography of Uneven Development". (Ph. D. diss., University of Toronto, 1991), especialmente p. 212-17.

Whigham, op. cit., p. 77 e 126. 


\section{Conclusão}

Por meio de extensas viagens pela América do Sul meridional, Aimé Bonpland abriu um canal evidente para a difusão de idéias sobre novas formas de uso da terra. Foi um plantador de sementes tanto em sentido literal quanto metafórico, numa região em que a audiência interessada em diversificação econômica era reduzidíssima. A despeito de uma história consistente de perdas econômicas na América do Sul, mesmo em idade avançada continuou a sonhar e fazer projetos de desenvolvimento agrícola. Um artista americano (daguerreotipista) que viajou com ele em 1850 disse à Société de Géographie de Paris, pouco tempo depois, que as discussões de Bonpland sobre projetos futuros davam ao interlocutor a impressão de que o cientista estivesse ainda "à la fleur de son âge". ${ }^{48}$

Bonpland teve poucos que o igualassem em trabalho de campo. Pesquisava continuamente e ninguém possuía mais experiência com as características das plantas de mate. Seus talentos incluíam a habilidade de aprender com os outros; ele reconheceu as realizações agrícolas dos jesuítas e viu as qualidades dos índios. Sentiu-se à vontade em sociedades notáveis pela polarização crescente entre cidade e campo, ou elites e povo.

Mas trabalhar só com acesso descontínuo a publicações européias impunha limitações, que ele reconhecia. Uma vida migratória dispersou suas energias e reduziu-lhes o impacto potencial. É óbvio que a política se atravessou em seu caminho, mas também que o dom de Bonpland para a avaliação minuciosa de recursos naturais não foi igualado por uma semelhante percepção das limitações da política governamental. O círculo sempre crescente de amizades resultante das contínuas andanças refletia uma curiosidade inquieta. Talvez fosse também uma estratégia de sobrevivência consciente no contexto político extremamente instável da região e do período.

Este trabalho examinou apenas uma fase do longo interesse de Bonpland pelo desenvolvimento de recursos, mas demonstrou que ele esteve à frente de sua época no pioneirismo e planos agrícolas. Por exemplo, seu interesse no cultivo de mate nas plantações não foi retomado até 1890, mas então em maior escala, em partes da Argentina, Paraguai e sul do Brasil. Seu posicionamento quanto a recursos florestais

48 "Nouvelles géographiques," BSG, 4" ser., 1 (janeiro 1851), p. 86-87. 
foi ainda mais perspicaz, aproximando-se da essência da idéia atual de desenvolvimento sustentável. Há sempre em seus escritos uma forte ênfase no desenvolvimento econômico local de recursos naturais de maneira sustentável. ${ }^{49}$ Sua preocupação com a proteção de recursos naturais foi em si mesma uma inovação na América do Sul meridional da metade do século dezenove; seus apelos, em grande parte caídos em ouvidos moucos, receberiam hoje maior atenção.

49 Ele argumentou, por exemplo, que algum estímulo governamental para o desenvolvimento de árvores ricas em cera poderia reverter a posição do Brasil de "tributaire de l'Europe" para esse produto; ver também seus comentários sobre como os habitantes do vale do Uruguai poderiam obter mais das palmeiras jataí (Cocos jataî) ao invés de destrui-las, Bonpland, op. cit., p. 29 e 87-88. 